\title{
新型丁烯内酯衍生物的设计合成及诱导胃癌细胞凋亡研究
}

\author{
徐海伟 \\ 李媛媛 \\ 董航歧 \\ 孟夏 \\ 赵玲洁 \\ 吕春涛王振亚* \\ 金成允* \\ (郑州大学药学院 药物关键制备技术教育部重点实验室 新药创制与药物安全性评价河南省协同创新中心 \\ 药物质量控制与评价河南省重点实验室 郑州 450001)
}

\begin{abstract}
摘要 开发了一条合成天然产物 Uncinine 的新方法, 基于此设计合成了一系列新型的丁烯内醌衍生物. 通过噻唑蓝 (MTT)法评价了目标化合物对胃癌细胞的增殖抑制活性，分析了其构效关系. 其中，3-吗啉甲基-4-(4-叔丁基苯基)亚基 丁烯内酯(91)对 $\mathrm{MGC} 803$ 的 $\mathrm{IC}_{50}$ 为 $2.9 \mu \mathrm{mol} / \mathrm{L}$, 对胃癌细胞 MGC803、HGC27 以及 SGC7901 具有明显的选择性增殖抑 制作用, 而对正常的胃粘膜上皮细胞 GES1 具有较小的毒性. 初步的作用机制研究表明, 化合物 91 诱导胃癌细胞 MGC803 调亡依赖 Caspase 9/3 激活.
\end{abstract}

关键词 丁烯内酯; 合成; 胃癌, 诱导调亡; Caspase

\section{Design and Synthesis of Novel Butenolide Derivatives and Inducing Apoptosis in Gastric Cancer Cells}

\author{
$\mathrm{Xu}$, Haiwei \\ Li, Yuanyuan \\ Dong, Hangqi \\ Meng, Xia \\ Zhao, Lingjie \\ Lü, Chuntao \\ Wang, Zhenya* \\ Jin, Chengyun*
}

(Key Laboratory of Drug Preparation Technologies, Ministry of Education, Key Laboratory of Henan Province for Drug Quality Control and Evaluation, Collaborative Innovation Center of New Drug Research and Safety Evaluation, School of Pharmaceutical Sciences, Zhengzhou University, Zhengzhou 450001)

\begin{abstract}
A new method of preparation for natural product Uncinine was reported. According to the method, a series of novel butenolides derivatives were designed and synthesized based on the natural product Uncinine. Most of the synthetic compounds showed significant anti proliferation activity against MGC-803. Among of them, (Z)-5-(4-(tert-butyl)benzylidene)-3-(morpholinomethyl)furan-2(5H)-one (9l) showed potent anticancer effect with $\mathrm{IC}_{50}$ of $2.9 \mu \mathrm{mol} / \mathrm{L}$ in gastric cancer cell MGC803 and showed good selectivity to gastric cancer cells MGC803, HGC27, SGC7901 and less cytotoxicity in normal gastric epithelial cell line (GES1). The research on the molecular level suggests that the mechanism of compound 91 inducing apoptosis in gastric cancer cells is partially dependent on activation of caspase-9/3.
\end{abstract}

Keywords butenolide; synthesis; gastric cancer; apoptosis, caspase

\section{Introduction}

The development of novel therapeutic drugs from medicinal plants has been one of the most important resource to drug development. Natural butenolides, such as aspulvione ${ }^{[1]}$ uncinine ${ }^{[2]}$ and so on including a similar structures BH3I- ${ }^{[3]}$ and obaloclax ${ }^{[4]}$ (Figure 1), have a wide range of biological activities, such as antibacterial, antiviral, anticancer, antimalarial, antibiotic and phospholipase A2 inhibition etc. ${ }^{[5]}$
In connection with previous studies concerning the synthesis and bioactivities of butenolide ${ }^{[6,7]}$ we are interested in discovery novel anticancer compounds based on the natural product uncinine. Gastric cancer (GC) is a highly aggressive malignant tumor, ${ }^{[8]}$ especially in East Asia, such as China, South Korea and Japan. Its high mortality rate prompts the urgent need for novel therapeutic agents. Focusing on GC, our group designed and synthesized novel butenolides and assayed their anti tumor activities. Most of

\footnotetext{
* Corresponding authors. E-mail: cyjin@zzu.edu.cn; barton118@163.com

Received July 12, 2019; revised August 14, 2019; published online September 18, 2019.

Project supported by the Natural Science Foundation of Henan Province (No. 182300410367), and the Scientific Innovation Talent Award from the Department of Education of Henan Province (No. 15HASTIT036).

河南省自然科学基金(No. 182300410367)和河南省高校科技创新人才(No. 15HASTIT036)资助项目.
} 
<smiles>CC(C)C(C(=O)O)C1C(=O)/C(=C/c2ccc(Br)cc2)SC1=S</smiles><smiles>CC(C)=C1C=C(CN2CCCC2=O)C(=O)O1</smiles>

Uncinine

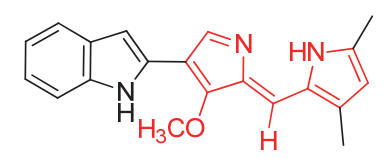

Obatoclax

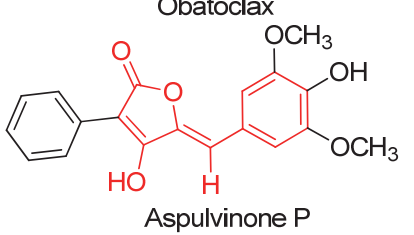

Figure 1 Structures of BH3I-1, obaloclax and selected natural butenolides

synthetic compounds showed significant anti proliferation activity against gastric cancer cells. Among of them, compound 91 was discovered with good and selective inhibition of proliferation on cancer cells by triggering apoptotic cell death. At the molecular level, compound 91 induced apoptosis in gastric cancer cells through dependent caspase activation.

\section{Results and discussion}

\subsection{Chemistry}

Uncinine (6) as a natural bioactive butenolide, could be synthesized according to literature procedures that is the only one work about its synthesis so far. ${ }^{[2]}$ However the method is deficient in low yield and many steps. In order to get more uncinine (6) and its analogues to research, a new route for preparation of Uncinine was designed and carried out via 4 steps with $30.4 \%$ yield shown in Scheme 1. Bromolactone $\mathbf{3}$ was obtained from the commercially available tulipalin (1) by bromination reaction followed by regioselective elimination. The bromination reaction was done in the present of $\mathrm{Me}_{3} \mathrm{PhN}^{+} \mathrm{Br}_{3}^{-}$(1.2 equiv.) at room temperature. The crude product 2 was treated with 5 equiv. of $\mathrm{LiBr} / \mathrm{Li}_{2} \mathrm{CO}_{3}$ in the present of TBAB in $\mathrm{CH}_{3} \mathrm{CN}$. By the above two steps reaction, compound $\mathbf{3}$ was obtained with a yield of $76 \%$. Compounds $\mathbf{4}$ and $\mathbf{5}$ were isolated as a mixture after completion of a nucleophilic substitution reaction of bromolactone 3 and ethyl 4-aminobutanoate hydrochloride. The mixture was stirred in acetone and methanol for $72 \mathrm{~h}$ at room temperature and purified by silicon chroma-

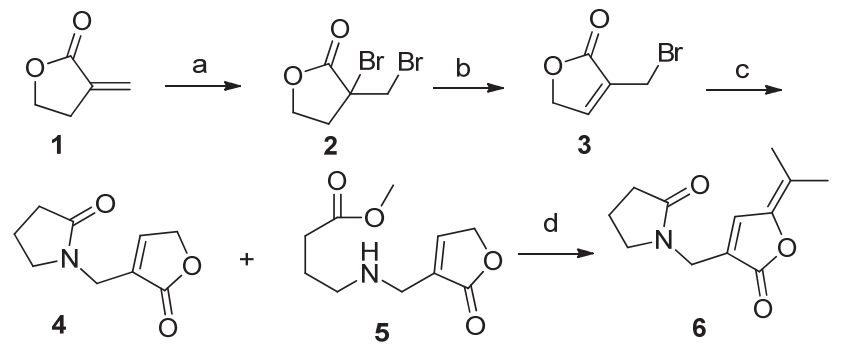

Reagents and conditions: (a) $\mathrm{Me}_{3} \mathrm{PhNBr}_{3}$, dioxane, r.t., $10 \mathrm{~h}$; (b) $\mathrm{LiBr} / \mathrm{Li}_{2} \mathrm{CO}_{3}$, TBAB, $\mathrm{CH}_{3} \mathrm{CN}$, r.t., 20 h; (c) ethyl 4-aminobutanoate hydrochloride, $\mathrm{Et}_{3} \mathrm{~N}$, dry THF, $0{ }^{\circ} \mathrm{C} \sim$ r.t., 26 h; (d) acetone, $\mathrm{CH}_{3} \mathrm{OH}$, r.t., $72 \mathrm{~h}$

Scheme 1 Synthesis of compound 6 tography to give Uncinine (6) with yield of $40 \%$ as a white solid.

Based on the intermediate 3, 3-(alkylamino)methyl)-5(propan-2-ylidene)furan-2(5H)-ones $(\mathbf{8 a} \sim \mathbf{8 g})$ were synthesized to investigate the structure activity relationship (SAR) of the pyrolidin-2-ones moiety in the Uncinine (6) by keeping the lactone and isopropyl group (Scheme 2). Different alkenes were introduced to $\mathrm{C}-5$ of $7 \mathbf{a}$ to replace the isopropanylidene group to prepare 5-benzylidene-3(morpholinomethyl)furan-2(5H)-ones $(9 \mathbf{9 a} \sim 90)$ and compound $9 \mathbf{p}$ in Scheme 3. The configurations of double bonds on C-5 of compounds 9a $\sim 90$ were cis-double bonds according to NMR and the previous works. ${ }^{[9,10]}$

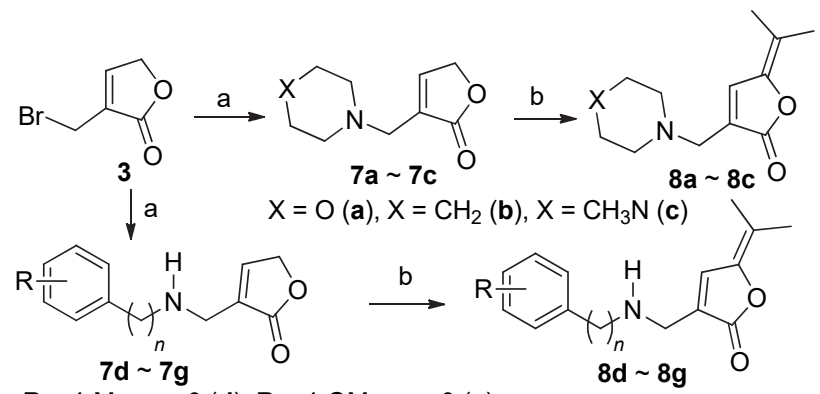

$\mathrm{R}=4-\mathrm{Me}, n=0$ (d); $\mathrm{R}=4-\mathrm{OMe}, n=0$ (e);

$\mathrm{R}=4-\mathrm{Me}, n=1$ (f); $\mathrm{R}=4-\mathrm{OMe}, n=\mathrm{I}(\mathbf{g})$

Reagents and conditions: (a) various substituted amine, $\mathrm{K}_{2} \mathrm{CO}_{3} /$ $\mathrm{Et}_{3} \mathrm{~N}$, THF, r.t., $2 \mathrm{~h}$; (b) Acetone, $\mathrm{CH}_{3} \mathrm{OH}$, reflux, $1 \mathrm{~h}$

Scheme 2 Synthesis of compound $\mathbf{8}$

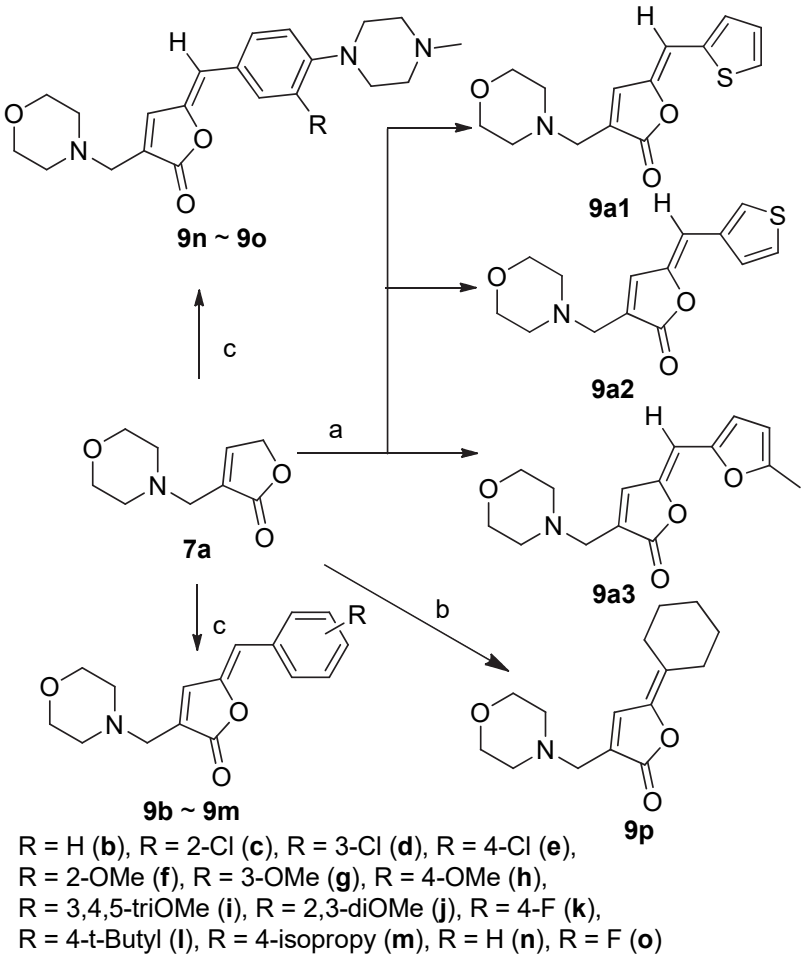

Reagents and conditions: (a) 5-methylfuran-2-carbaldehyde, ethylenediamine, $\mathrm{CH}_{3} \mathrm{OH}$, reflux; (b) cyclohexanone, ethylenediamine, $\mathrm{CH}_{3} \mathrm{OH}$, reflux; (c) substitued benzaldehyde, ethylenediamine, $\mathrm{CH}_{3} \mathrm{OH}$, reflux

Scheme 3 Synthesis of compound 9 
Among of synthetic compounds, compound 91 showed potent anticancer effect in gastric cancer MGC803 and less cytotoxicity in normal gastric epithelial cell line (GES1). Compound 91 has a 4-isopropyl phenyl group in its structure. So two another compounds with 4-isopropyl phenyl methyl indene indol-2-ones were synthesized (Scheme 4).

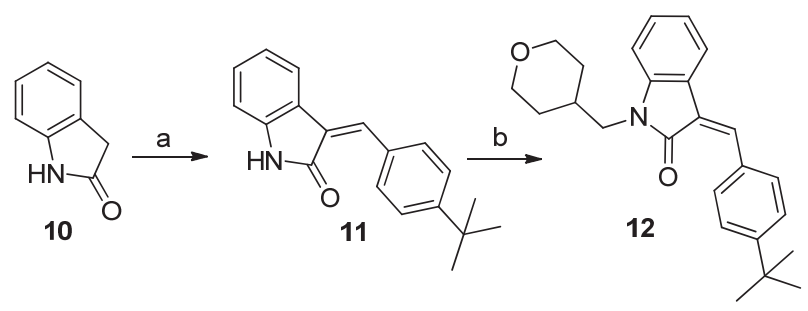

Reagents and conditions: (a) 4-butylbenzaldehyde, ethylenediamine, $\mathrm{CH}_{3} \mathrm{OH}$, reflux; (b) 4-bromomethyl-tetrahy-dro-2H-pyran, DMF, $\mathrm{NaH}, \mathrm{O}{ }^{\circ} \mathrm{C} \sim$ r.t.

Scheme 4 Synthesis of compounds 11 and 12

\subsection{Biology}

\subsubsection{Evaluation of antiproliferation on MGC803}

Anti-proliferation of compounds $\mathbf{8 a} \sim \mathbf{8 g}$ is evaluated in vitro on MGC803. The results are reported in Table 1. Just compound 8a shows inhibition on the tested cancer cells with $\mathrm{IC}_{50}$ of $42.7 \mu \mathrm{mol} / \mathrm{L}$. Uncinine (6) and compounds $\mathbf{8 b} \sim \mathbf{8 g}$ show no significant anti-proliferative activity on MGC803. Based on the above results, compounds $\mathbf{9 a} \sim \mathbf{9 p}$ are synthesized and assayed to optimize the structure of compound 8a. The anti-proliferation of compounds $9 \mathbf{a} \sim$ $9 \mathbf{p}$ are listed in Table 1, and most of them give better anti-proliferation than compound 8a. Compounds 9a1 $\sim 9 a 3$ with furan have no anti-proliferation on MGC803 cell. Among them compound 91 is the best one with $\mathrm{IC}_{50}$ of 2.9 $\mu \mathrm{mol} / \mathrm{L}$. Compounds $\mathbf{1 1}$ and $\mathbf{1 2}$ with similar substituted phenyl group can inhibit proliferation of MGC803 with $\mathrm{IC}_{50}$ of 7.5 and $12.3 \mu \mathrm{mol} / \mathrm{L}$ which are less than compound 9l. Therefore compound 91 is chosen to evaluate further.

The SAR of synthetic compounds for anti-proliferation on MGC803 suggests that morpholine aminomethyl group on carbon-3 of butenolide is beneficial to the bioactivity (such as compound 8a). As for the substitution on carbon-5 butenolide, phenyl groups on the structures of compounds $\mathbf{9 b} \sim 9 \mathbf{q}$, play more important role than the furan heterocyclic groups on the structures of compounds 9a1 $\sim 9 \mathbf{9 3}$.
Among the substituted groups on the phenyl group for compounds $9 \mathbf{b} \sim 9 \mathbf{q}$, hydrophilic groups on carbon-4 of phenyl are better than others, such as compounds 91 and 9m.

2.2.2 Caspase-dependent apoptosis was induced by compound 91 in MGC803 cells

Compound 91 was proved hypotoxicity in normal human gastric epithelial cell line (GES1) and showed a selectivity to gastric cancer cells (MGC803, SGC7901 and HGC27) comparing with GES1 cells (Figure 2A). Based on the above results, compound 9l was prioritized to perform further experiment for evaluating its anti-cancer potential in gastric cancer.

Morphological changes of MGC803 cells were determined by use of 4,6-diamidino-2-phenylindole (DAPI) staining, as shown in Figure 2B. An increasing number of cells with chromatin condensation were observed in compound 91-treated MGC803 cells in a dose-dependent manner. Chromatin condensation was not observed in the untreated control cells, suggesting that compound 9l-induced cell death is related to apoptosis. We evaluated apoptotic induction in MGC803 by compound 91 with annexin V and propidium iodide (PI) staining. It was found that the number of annexin V-positive cells showed a dose-dependent increase from $8.6 \%$ to $49.5 \%$ in MGC803 cells, whereas treatment of control cells only resulted in a $5.2 \%$ increase in annexin V-positive stained cells (Figure 2C). These data suggested that apoptosis was induced by compound 91 in MGC803 cells. The apoptosis-related proteins were deteted by wester blot analysis in cells treated with compound 91. Caspase-3, caspase-9, and poly(ADP-ribose) polymerase (PARP-1) proteins were down regulated, whereas cleaved caspase- 9 protein was up regulated by compound 9l compared with control MGC803 cells (Figure 2D). To further evaluate the significance of caspase activation in compound 9l-induced apoptosis, z-VAD-fmk $(100 \mu \mathrm{mol} / \mathrm{L})$, an irreversible pan-caspase inhibitor, was used to pretreat MGC803 cells for $1 \mathrm{~h}$, followed by treatment with $20 \mu \mathrm{mol} / \mathrm{L}$ compound 91 for $24 \mathrm{~h}$. Morphological changes of MGC803 cells were then determined by DAPI staining, as shown in Figure 2E. A significant number of cells with chromatin condensation were observed in cells treated with compound 91, and these features were almost invisible in cells pretreated with z-VAD-fmk (100

Table 1 Antiproliferative activity of synthetic compounds on MGC803

\begin{tabular}{cc||cc||cc||cc}
\hline Compd. & $\mathrm{IC}_{50}{ }^{a} /\left(\mu \mathrm{mol} \cdot \mathrm{L}^{-1}\right)$ & Compd. & $\mathrm{IC}_{50}{ }^{a} /\left(\mu \mathrm{mol} \cdot \mathrm{L}^{-1}\right)$ & Compd. & $\mathrm{IC}_{50}{ }^{a} /\left(\mu \mathrm{mol} \cdot \mathrm{L}^{-1}\right)$ & Compd. & $\mathrm{IC}_{50}{ }^{a} /\left(\mu \mathrm{mol} \cdot \mathrm{L}^{-1}\right)$ \\
\hline $\mathbf{8 a}$ & $42.7 \pm 3.1$ & $\mathbf{9 a 1}$ & $>50$ & $\mathbf{9 f}$ & $28.1 \pm 3.1$ & $\mathbf{9 m}$ & $5.6 \pm 0.8$ \\
$\mathbf{8 b}$ & $>128$ & $\mathbf{9 a 2}$ & $44.4 \pm 1.6$ & $\mathbf{9 g}$ & $14.7 \pm 2.1$ & $\mathbf{9 n}$ & $17.1 \pm 1.2$ \\
$\mathbf{8 c}$ & $>128$ & $\mathbf{9 a 3}$ & $>128$ & $\mathbf{9 h}$ & $13.3 \pm 2.1$ & $\mathbf{9 0}$ & $26.7 \pm 1.4$ \\
$\mathbf{8 d}$ & $>128$ & $\mathbf{9 b}$ & $23.1 \pm 2.9$ & $\mathbf{9 i}$ & $26.3 \pm 2.7$ & $\mathbf{9 p}$ & $23.0 \pm 1.4$ \\
$\mathbf{8 e}$ & $>128$ & $\mathbf{9 c}$ & $18.6 \pm 2.5$ & $\mathbf{9 j}$ & $19.3 \pm 2.2$ & $\mathbf{1 1}$ & $7.5 \pm 0.9$ \\
$\mathbf{8 f}$ & $>128$ & $\mathbf{9 d}$ & $10.9 \pm 1.7$ & $\mathbf{9 k}$ & $20.4 \pm 1.2$ & $\mathbf{1 2}$ & $12.4 \pm 1.1$ \\
$\mathbf{8 g}$ & $119.8 \pm 3.5$ & $\mathbf{9 e}$ & $23.2 \pm 2.9$ & $\mathbf{9 l}$ & $2.9 \pm 0.1$ & & \\
$5-\mathrm{Fu}^{b}$ & $7.1 \pm 1.3$ & Uncinine & $>128$ & & & & \\
\hline
\end{tabular}

${ }^{a}$ MTT assay: All data are mean values from triplicate experiments. ${ }^{b}$ Positive control: fluorouracil. 
(A)

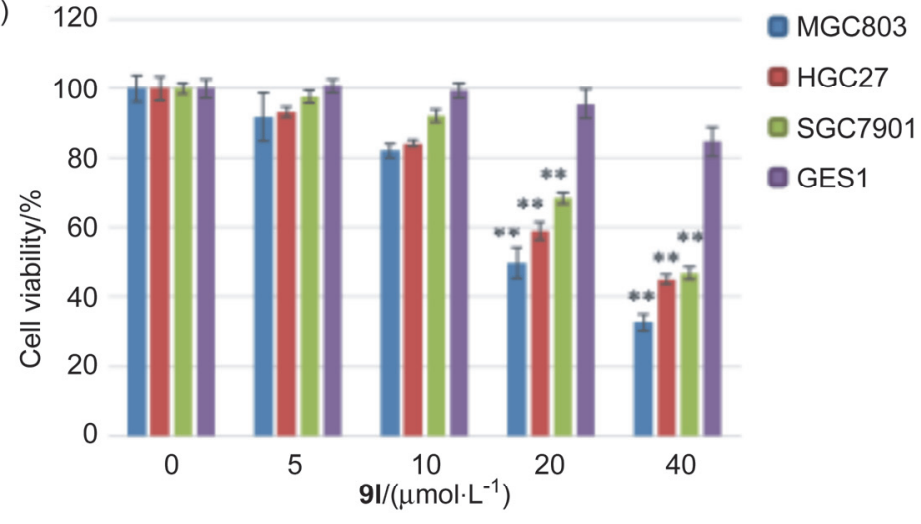

(C)

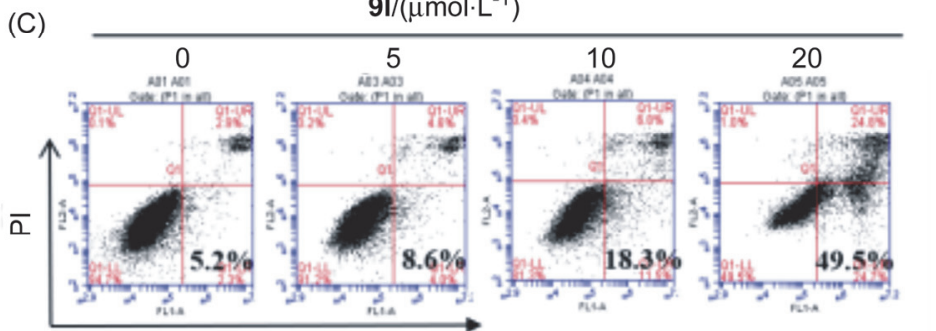

(B)

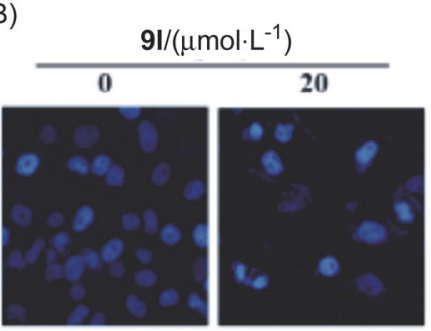

(D)

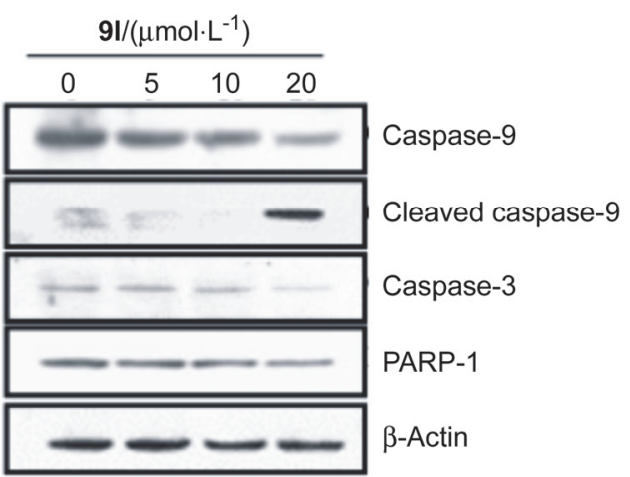

(E)
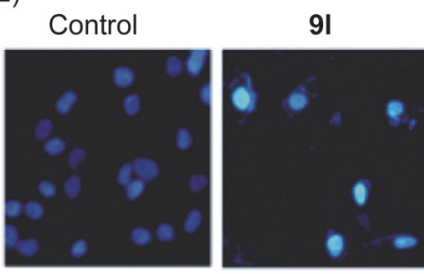

(F)
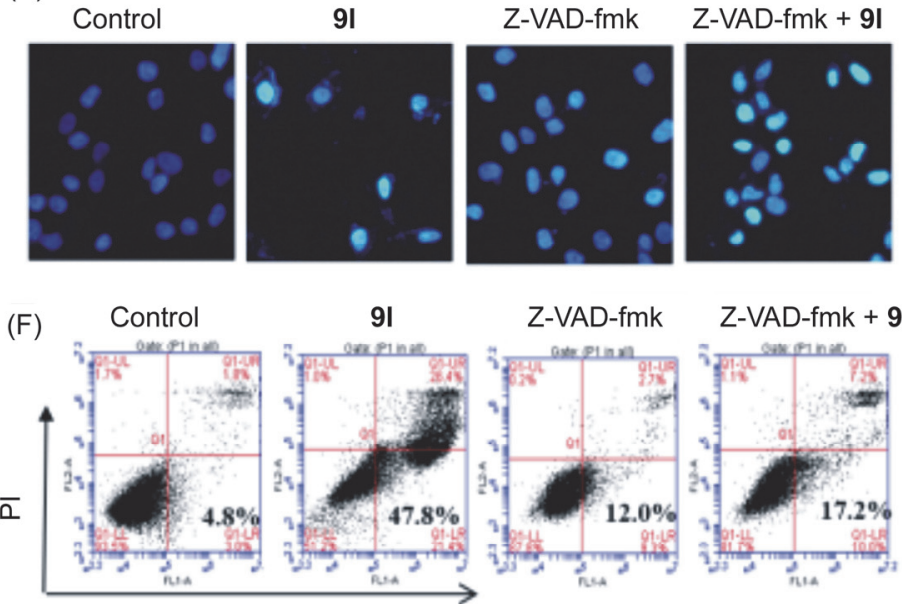

Z-VAD-fmk + 9l

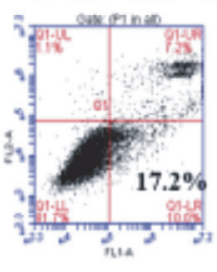

Annexin V-FITC

Figure 2 Apoptosis induced by compound 91 in MGC803 cells

(A) The cytotoxicity of compound $9 \mathrm{l}$ by MTT assay. Cells were treated with indicated concentrations for $24 \mathrm{~h} .{ }^{* *} P<0.01$ vs. untreated group. (B) MGC803 cells were incubated with compound $9 \mathrm{l}(20 \mu \mathrm{mol} / \mathrm{L})$ for $24 \mathrm{~h}$, and then stained with DAPI. The stained nuclei were observed under a fluorescent microscope (magnification, $\times 200$ ). (C) A dose-dependent induction of apoptosis by compound 91 was demonstrated in MGC 803 cells by flow cytometric analysis of annexin V/PI stain assay. (D) The effects of compound 9l-induced $(20 \mu \mathrm{mol} / \mathrm{L})$ protein changes were detected by Western blot analysis for $24 \mathrm{~h}$ in MGC803 cells. (E) The effects of caspase inhibitor Z-VAD-fmk $(100 \mu \mathrm{mol} / \mathrm{L})$ on compound 9 l-induced $(20 \mu \mathrm{mol} / \mathrm{L})$ apoptosis of MGC803 cells were shown through DAPI solution (magnification, $\times 200$ ). (F) Annexin V/PI stained cells showed the effects of caspase inhibitor Z-VAD-fmk $(100 \mu \mathrm{mol} / \mathrm{L})$ on compound 91 -induced $(20 \mu \mathrm{mol} / \mathrm{Lol} / \mathrm{L})$ apoptosis of MGC 803 cells

$\mu \mathrm{mol} / \mathrm{L})$ followed by treatment with $20 \mu \mathrm{mol} / \mathrm{L}$ compound 9l. In Figure $2 \mathrm{~F}$, compound $9 \mathrm{l}$-induced apoptosis was reduced from $47.8 \%$ to $17.2 \%$ by pretreatment with z-VAD-fmk (100 $\mu \mathrm{mol} / \mathrm{L})$, according to flow cytometry analysis.

The activity of caspases is the molecular hallmark of apoptosis and is a controlling factor in the apoptotic cascade. ${ }^{[1,12]}$ Thus, caspase activity is considered in compound 9l-induced apoptosis. Caspase-9 is the initiating enzyme of the apoptotic pathway, and caspase- 3 is the key executioner caspase and is activated through cleavage of caspase-9. ${ }^{[13]}$ The activity of these factors can be indirectly measured at the protein expression by Western blot analysis. Fulda et al. ${ }^{[14]}$ found that resveratrol-induced apoptosis was triggered by the activation of caspases and reversed by pretreatment with the caspase inhibitor Z-VAD-fmk. In this study, the results showed that the expressions of caspase- 3 and caspase- 9 were decreased by increasing compound 91 concentrations. Compound 91 induced apoptosis in gastric cancer cells through dependent caspase ac- 
tivation.

\section{Conclusions}

In summary, based on the active natural products butenolide, an effective anti cancer agent compound 9l in gastric cancer was found. The results suggested that apoptosis was involved in compound 9l-induced gastric cancer cell death. The potential mechanisms of compound 91 have resulted from the induction of apoptosis as evidenced by partially dependent caspase activation. It deserves further investigation into it utility for prevention and treatment of gastric cancer.

\section{Experimental}

\subsection{Chemistry}

All solvents and reagents were purchased from commercial sources, generally with no need of drying and/or purification unless necessary. Melting points were determined on a Beijing Fukai X-5 apparatus and were uncorrected. ${ }^{1} \mathrm{H}$ NMR and ${ }^{13} \mathrm{C}$ NMR spectra were recorded on a Bruker DPX-400 spectrometer at 400 and $100 \mathrm{MHz}$ with TMS as internal standard. HRMS was recorded on a Q-Tof Micro HRMS of waters.

4.1.1 Synthesis of 3-(bromomethyl)furan-2(5H)-one (3)

Thimethylphenylammonium tribromide $\left(\mathrm{Me}_{3} \mathrm{PhN}^{+} \mathrm{Br}_{3}^{-}\right)$ (13.8 g, $36.7 \mathrm{mmol}$ ) was added to the solution of $\alpha$-methylene- $\gamma$-butene lactone (3 g, $30.6 \mathrm{mmol}$ ) in dioxane $(90 \mathrm{~mL})$. The reaction mixture was stirred for $10 \mathrm{~h}$ at room temperature. The reaction was monitored by TLC until all $\alpha$-methylene- $\gamma$-butene lactone was consumed. Upon completion, the reaction mixture was diluted with $250 \mathrm{~mL}$ of diethyl ether and filtered. The filtrate was concentrated under reduced pressure. Without purification, the above crude product, $\mathrm{Li}_{2} \mathrm{CO}_{3}(11.1 \mathrm{~g}, 150 \mathrm{mmol}), \mathrm{LiBr}(15.6 \mathrm{~g}$, $150 \mathrm{mmol})$ and tetrabutylammonium bromide $(0.966 \mathrm{~g}, 3$ mmol) were suspended in $\mathrm{CH}_{3} \mathrm{CN}(90 \mathrm{~mL})$. The mixture was stirred at $85{ }^{\circ} \mathrm{C}$ for $20 \mathrm{~h}$. The reaction was monitored by TLC. After filtering and removing the spare solvent under vacuum, the residue was dissolved in $300 \mathrm{~mL}$ of diethyl ether and washed with saturated salt water (150 $\mathrm{mL})$. The organic phase was dried over anhydrous $\mathrm{Na}_{2} \mathrm{SO}_{4}$ and then concentrated. The concentrate was purified by column chromatography (petroleum ether/acetic ether, $V$ : $V=5: 1)$ to afford the product $3{ }^{[15]}$ Yellow oil, yield 4.09 g $(76 \%) .{ }^{1} \mathrm{H}$ NMR $\left(400 \mathrm{MHz}, \mathrm{CDCl}_{3}\right) \delta: 7.55(\mathrm{~s}, 1 \mathrm{H}), 4.89$ (d, $J=1.7 \mathrm{~Hz}, 2 \mathrm{H}), 4.13(\mathrm{~d}, J=1.4 \mathrm{~Hz}, 2 \mathrm{H})$.

\subsubsection{Synthesis of compounds $\mathbf{4}$ and $\mathbf{5}$}

Compound 3 (0.5 g, $2.82 \mathrm{mmol})$ in dry tetrahydrofuran (THF) $(5 \mathrm{~mL})$ was added dropwise in four portions to a solution of ethyl- $\gamma$-aminobutyrate hydrochloride $(0.72 \mathrm{~g}$, $7.23 \mathrm{mmol})$ and triethylamine $(0.86 \mathrm{~g}, 8.74 \mathrm{mmol})$ in dry THF $(10 \mathrm{~mL})$ at $0{ }^{\circ} \mathrm{C}$ over $2 \mathrm{~h}$. The reaction mixture was then warmed to room temperature, stirred for another $24 \mathrm{~h}$. After the reaction completion, the solid was filtered off, and the solvent was removed on a rotary evaporator. The crude product was mixture of compounds $\mathbf{4}$ and $\mathbf{5}$, which were used directly to the next step.

\subsubsection{Synthesis of uncinine (6)}

The mixture of 4, $5(0.576 \mathrm{~g})$ and acetone $(5 \mathrm{~mL})$ was added to a solution of methyl alcohol $(10 \mathrm{~mL})$, and the reaction mixture was stirred at room temperature for 72 hours. The reaction system was filtered and the solvent was evaporated in vacuo. The reaction mixture was then diluted with diethyl ether $(30 \mathrm{~mL} \times 3)$, and washed with $\mathrm{H}_{2} \mathrm{O}(50 \mathrm{~mL})$. The organic phase was dried over anhydrous $\mathrm{Na}_{2} \mathrm{SO}_{4}$, and the solvent was removed. The crude product was purified by column chromatography on silica gel $[V$ (petroleum ether) : $V$ (acetone $)=6: 1]$ to afford the product $6^{[2]}$ as a white crystalline substance $(0.249 \mathrm{~g}$, white solid). Yield 40\%. ${ }^{1} \mathrm{H}$ NMR $\left(400 \mathrm{MHz}, \mathrm{CDCl}_{3}\right) \delta: 7.49$ (s, $1 \mathrm{H}), 4.19(\mathrm{~s}, 2 \mathrm{H}), 3.48(\mathrm{~m}, 2 \mathrm{H}), 2.40(\mathrm{~m}, 2 \mathrm{H}), 2.08 \sim 2.01$ $(\mathrm{m}, 2 \mathrm{H}), 2.00(\mathrm{~s}, 3 \mathrm{H}), 1.92(\mathrm{~s}, 3 \mathrm{H})$.

\subsubsection{Synthesis of compounds $7 \mathbf{a} \sim 7 \mathbf{e}$}

Nitrogen compounds $(3 \mathrm{mmol})$ were diluted with $1 \mathrm{~mL}$ of THF and then slowly dropped into the THF solution (1 $\mathrm{mL}$ ) of compound 3 (400 $\mathrm{mg}, 2.27 \mathrm{mmol}$ ) with a lot of white solid precipitated. The reaction mixture was stirred at room temperature. After completion of the reaction, the reaction system was filtered, concentrated under vacuum and crystallized from ethyl acetate to yield the pure products $7 \mathbf{a} \sim 7 \mathbf{7 e}$, which directly used for the next reaction.

\subsubsection{General procedure for the synthesis of uncinine} analogues $\mathbf{8 a} \sim \mathbf{8 e}$

The corresponding compounds $\mathbf{7 a} \sim \mathbf{7 e}$ were dissolved in methanol and then refluxed with appropriate acetone at $65{ }^{\circ} \mathrm{C}$ for $1 \mathrm{~h}$. The reaction was monitored by TLC. After the reaction completed, the reaction mixture was evaporated in vacuo and purified by column chromatography to afford the pure product $\mathbf{8 a} \sim \mathbf{8 e}$.

3-(Morpholinomethyl)-5-(propan-2-ylidene)furan2(5H)-one (8a): Light yellow solid, yield 60\%. ${ }^{1} \mathrm{H}$ NMR $\left(400 \mathrm{MHz}, \mathrm{CDCl}_{3}\right) \delta: 6.10(\mathrm{~s}, 1 \mathrm{H}), 3.76 \sim 3.67(\mathrm{~m}, 4 \mathrm{H})$, $3.44(\mathrm{~s}, 2 \mathrm{H}), 2.55 \sim 2.46(\mathrm{~m}, 4 \mathrm{H}), 2.04(\mathrm{~s}, 3 \mathrm{H}), 2.05(\mathrm{~s}$, $3 \mathrm{H}) .{ }^{13} \mathrm{C} \mathrm{NMR}\left(101 \mathrm{MHz}, \mathrm{CDCl}_{3}\right) \delta: 144.8,134.6,129.9$, 127.6, 122.5, 113.4, 39.9, 29.7, 20.4, 18.7. HRMS (ESI) calcd for $\mathrm{C}_{12} \mathrm{H}_{18} \mathrm{NO}_{3}[\mathrm{M}+\mathrm{H}]^{+}$224.1281, found 224.1292.

3-(Piperidin-1-ylmethyl)-5-(propan-2-ylidene)furan2(5H)-one (8b): Light yellow solid, yield 50\%. ${ }^{1} \mathrm{H}$ NMR $\left(400 \mathrm{MHz}, \mathrm{CDCl}_{3}\right) \delta: 7.54(\mathrm{~s}, 1 \mathrm{H}), 3.32$ (s, 2H), 2.48 (brs, 4H), 2.02 (s, 3H), 1.96 (s, 3H), 1.63 (brs, 4H), 1.50 1.42 $(\mathrm{m}, 2 \mathrm{H}) ;{ }^{13} \mathrm{C} \mathrm{NMR}\left(101 \mathrm{MHz}, \mathrm{CDCl}_{3}\right) \delta: 170.8,144.9$, 136.1, 128.6, 121.9, 54.5, 53.1, 29.7, 25.8, 24.1, 18.6. HRMS (ESI) calcd for $\mathrm{C}_{13} \mathrm{H}_{20} \mathrm{NO}_{2}[\mathrm{M}+\mathrm{H}]^{+}$222.1489, found 222.1483 .

3-((4-Methylpiperazin-1-yl)methyl)-5-(propan-2-ylidene)furan-2(5H)-one $(\mathbf{8 c})$ : Light yellow solid, yield $63 \% .{ }^{1} \mathrm{H}$ NMR (400 MHz, $\left.\mathrm{CDCl}_{3}\right) \delta: 7.48(\mathrm{~s}, 1 \mathrm{H}), 3.35(\mathrm{~s}, 2 \mathrm{H}), 2.57$ (brs, 8H), 2.32 (s, 3H), 2.01 (s, 3H), 1.95 (s, 3H). HRMS (ESI) calcd for $\mathrm{C}_{13} \mathrm{H}_{21} \mathrm{~N}_{2} \mathrm{O}_{2}[\mathrm{M}+\mathrm{H}]^{+}$237.1598, found 


\subsection{5.}

5-(Propan-2-ylidene)-3-(( $p$-tolylamino)methyl)furan2(5H)-one (8d): White solid, yield $50 \%$. ${ }^{1} \mathrm{H}$ NMR (400 $\left.\mathrm{MHz}, \mathrm{CDCl}_{3}\right) \delta: 7.42(\mathrm{~s}, 1 \mathrm{H}), 6.81(\mathrm{~d}, J=8.9 \mathrm{~Hz}, 2 \mathrm{H})$, $6.62(\mathrm{~d}, J=8.9 \mathrm{~Hz}, 2 \mathrm{H}), 4.11(\mathrm{~s}, 2 \mathrm{H}), 2.43(\mathrm{~s}, 3 \mathrm{H}), 2.01(\mathrm{~s}$, $3 \mathrm{H}), 1.91(\mathrm{~s}, 3 \mathrm{H}) ;{ }^{13} \mathrm{C} \mathrm{NMR}\left(101 \mathrm{MHz}, \mathrm{CDCl}_{3}\right) \delta: 170.1$, $152.7,144.7,141.2,134.6,129.9,122.5,114.9,114.7$, 55.7, 40.5, 29.7, 18.7. HRMS (ESI) calcd for $\mathrm{C}_{15} \mathrm{H}_{18} \mathrm{NO}_{2}$ $[\mathrm{M}+\mathrm{H}]^{+}$244.1332, found 244.1314.

3-(((4-Methoxyphenyl)amino)methyl)-5-(propan-2ylidene)furan-2(5H)-one (8e): Light yellow solid, yield 55\%. ${ }^{1} \mathrm{H}$ NMR (400 MHz, $\left.\mathrm{CDCl}_{3}\right) \delta: 7.42(\mathrm{~s}, 1 \mathrm{H}), 7.09(\mathrm{~d}$, $J=8.9 \mathrm{~Hz}, 2 \mathrm{H}), 6.72(\mathrm{~d}, J=8.9 \mathrm{~Hz}, 2 \mathrm{H}), 4.11(\mathrm{~s}, 2 \mathrm{H}), 3.77$ $(\mathrm{s}, 3 \mathrm{H}), 2.01(\mathrm{~s}, 3 \mathrm{H}), 1.91(\mathrm{~s}, 3 \mathrm{H}) ;{ }^{13} \mathrm{C} \mathrm{NMR}(101 \mathrm{MHz}$, $\left.\mathrm{CDCl}_{3}\right) \delta: 170.5,144.8,136.4,129.6,127.7,122.8,122.7$, $114.9,114.7,66.7,52.7,29.4,18.7$. HRMS (ESI) calcd for $\mathrm{C}_{15} \mathrm{H}_{18} \mathrm{NO}_{3}[\mathrm{M}+\mathrm{H}]^{+}$260.1281, found 260.1273.

3-(((4-Methylbenzyl)amino)methyl)-5-(propan-2ylidene)furan-2(5H)-one (8f): White solid, yield $70 \%{ }^{1} \mathrm{H}$ NMR (400 MHz, $\left.\mathrm{CDCl}_{3}\right) \delta: 7.42(\mathrm{~s}, 1 \mathrm{H}), 7.02(\mathrm{~d}, J=8.1$ $\mathrm{Hz}, 2 \mathrm{H}), 6.57$ (d, $J=8.4 \mathrm{~Hz}, 2 \mathrm{H}), 4.13$ (s, 2H), 3.79 (s, 2H), $2.26(\mathrm{~s}, 3 \mathrm{H}), 2.01(\mathrm{~s}, 3 \mathrm{H}), 1.90(\mathrm{~s}, 3 \mathrm{H})$. HRMS (ESI) calcd for for $\mathrm{C}_{16} \mathrm{H}_{20} \mathrm{NO}_{2}[\mathrm{M}+\mathrm{H}]^{+}$258.1489, found 258.1476.

3-(((4-Methoxybenzyl)amino)methyl)-5-(propan-2ylidene)furan-2(5H)-one (8g): Yellow solid, yield $75 \%$. ${ }^{1} \mathrm{H}$ NMR (400 MHz, $\left.\mathrm{CDCl}_{3}\right) \delta: 7.42(\mathrm{~s}, 1 \mathrm{H}), 6.81(\mathrm{~d}, J=8.9$ $\mathrm{Hz}, 2 \mathrm{H}), 6.62$ (d, $J=8.9 \mathrm{~Hz}, 2 \mathrm{H}), 4.28$ (s, 2H), 4.11 (s, 2H), 3.76 (s, 3H), $2.01(\mathrm{~s}, 3 \mathrm{H}), 1.91$ (s, 3H). HRMS (ESI) calcd for $\mathrm{C}_{16} \mathrm{H}_{20} \mathrm{NO}_{3}[\mathrm{M}+\mathrm{H}]^{+}$274.1438, found 274.1467. 4.1.6 General procedure for the synthesis of compounds $9 \mathbf{a} \sim 9 \mathbf{p}$

In a round-bottomed flask with a magneton, compound 7 a $(183 \mathrm{mg}, 1 \mathrm{mmol})$, substituted aldehyde or ketone (1 $\mathrm{mmol})$, ethanediamine $(6 \mathrm{mg}, 0.1 \mathrm{mmol})$ and methanol $(0.4$ $\mathrm{mL}$ ) were added. The reaction system was stirred at room temperature for $36 \mathrm{~h}$. The progress was detected by thin-layer chromatography (TLC). Upon completion, a lot of solid were filtered, dried and crystallized from methanol.

(Z)-3-(Morpholinomethyl)-5-(thiophen-2-ylmethylene)furan-2(5H)-one (9a1): Yellow soild, yield 11\%. ${ }^{1} \mathrm{H}$ NMR $\left(400 \mathrm{MHz}, \mathrm{CDCl}_{3}\right) \delta: 7.49(\mathrm{~d}, J=5.1 \mathrm{~Hz}, 1 \mathrm{H}), 7.37(\mathrm{~d}, J=$ $3.7 \mathrm{~Hz}, 1 \mathrm{H}), 7.33$ (s, 1H), 7.07 (dd, $J=5.0,3.8 \mathrm{~Hz}, 1 \mathrm{H})$, $6.28(\mathrm{~s}, 1 \mathrm{H}), 3.77 \sim 3.69(\mathrm{~m}, 4 \mathrm{H}), 3.36(\mathrm{~s}, 2 \mathrm{H}), 2.56 \sim 2.48$ $(\mathrm{m}, 4 \mathrm{H}) ;{ }^{13} \mathrm{C}$ NMR $\left(101 \mathrm{MHz}, \mathrm{CDCl}_{3}\right) \delta: 169.6,145.6$, 140.0, 136.2, 131.0, 130.4, 128.7, 127.8, 106.8, 66.9, 53.6, 52.9. HRMS (ESI) calcd for $\mathrm{C}_{14} \mathrm{H}_{16} \mathrm{NO}_{3} \mathrm{~S}[\mathrm{M}+\mathrm{H}]{ }^{+}$ 278.0845, found 278.0856.

(Z)-3-(Morpholinomethyl)-5-(thiophen-3-ylmethylene)furan-2(5H)-one (9a2): Yellow soild. ${ }^{1} \mathrm{H}$ NMR (400 MHz, $\left.\mathrm{CDCl}_{3}\right) \delta: 7.72(\mathrm{t}, J=3.9 \mathrm{~Hz}, 1 \mathrm{H}), 7.52(\mathrm{dd}, J=11.2,7.0$ $\mathrm{Hz}, 1 \mathrm{H}), 7.34$ (dd, $J=4.3,2.1 \mathrm{~Hz}, 1 \mathrm{H}), 7.33$ (s, 1H), 6.09 (s, 1H), 3.77 3.70 (overlap, 4H), 3.36 (s, 2H), 2.52 (brs, $4 \mathrm{H}) ;{ }^{13} \mathrm{C}$ NMR $\left(101 \mathrm{MHz}, \mathrm{CDCl}_{3}\right) \delta: 170.0,146.4,140.8$, $134.4,128.8,128.5,128.2,126.2,107.4,66.9,53.6,52.8$.
HRMS (ESI) calcd for $\mathrm{C}_{14} \mathrm{H}_{16} \mathrm{NO}_{3} \mathrm{~S}[\mathrm{M}+\mathrm{H}]^{+}$278.0845, found 278.0857 .

(Z)-5-((5-Methylfuran-2-yl)methylene)-3-(morpholinomethyl)furan-2(5H)-one (9a3): Brown solid, yield 75\%. m.p. $114 \sim 115{ }^{\circ} \mathrm{C} ;{ }^{1} \mathrm{H}$ NMR $\left(400 \mathrm{MHz}, \mathrm{CDCl}_{3}\right) \delta: 8.05(\mathrm{~s}$, $1 \mathrm{H}), 6.46$ (d, $J=3.2 \mathrm{~Hz}, 1 \mathrm{H}), 6.34(\mathrm{~s}, 1 \mathrm{H}), 6.11(\mathrm{~d}, J=3.1$ $\mathrm{Hz}, 1 \mathrm{H}), 3.79 \sim 3.76(\mathrm{~m}, 4 \mathrm{H}), 3.43(\mathrm{~s}, 2 \mathrm{H}), 2.61 \sim 2.56(\mathrm{~m}$, 4H), $2.42(\mathrm{~s}, 3 \mathrm{H}) ;{ }^{13} \mathrm{C}$ NMR (101 MHz, $\left.\mathrm{CDCl}_{3}\right) \delta: 169.6$, 155.3, 147.9, 146.1, 138.4, 116.6, 108.9, 102.6, 66.9, 53.6, 52.9 , 14.8. HRMS (ESI) calcd for $\mathrm{C}_{15} \mathrm{H}_{18} \mathrm{NO}_{4}[\mathrm{M}+\mathrm{H}]^{+}$ 276.1230 , found 276.1238 .

(Z)-5-Benzylidene-3-(morpholinomethyl)furan-2(5H)one (9b): White solid, yield 30\%. m.p. $145 \sim 146{ }^{\circ} \mathrm{C} ;{ }^{1} \mathrm{H}$ NMR (400 MHz, $\left.\mathrm{CDCl}_{3}\right) 7.79$ (s, 1H), 7.35 7.38 (overlap, 5H), $6.02(\mathrm{~s}, 1 \mathrm{H}), 3.80 \sim 3.73(\mathrm{~m}, 4 \mathrm{H}), 3.40(\mathrm{~s}, 2 \mathrm{H})$, $2.61 \sim 2.52(\mathrm{~m}, 4 \mathrm{H}) ;{ }^{13} \mathrm{C}$ NMR $\left(101 \mathrm{MHz}, \mathrm{CDCl}_{3}\right) \delta$ : $170.2,147.3,141.4,133.0,130.4,129.1,128.9,128.9$, $128.7,113.5,66.9,53.6,52.8$. HRMS (ESI) calcd for $\mathrm{C}_{16} \mathrm{H}_{18} \mathrm{NO}_{3}[\mathrm{M}+\mathrm{H}]^{+}$272.1281, found 272.1273.

(Z)-5-(2-Chlorobenzylidene)-3-(morpholinomethyl)furan-2(5H)-one (9c): White solid, yield 35\%. m.p. 147 $148{ }^{\circ} \mathrm{C} ;{ }^{1} \mathrm{H}$ NMR $(400 \mathrm{MHz}, \mathrm{CDCl} 3) \delta: 7.34 \sim 7.36$ (overlap, $5 \mathrm{H}), 6.51(\mathrm{~s}, 1 \mathrm{H}), 3.87 \sim 3.68(\mathrm{~m}, 4 \mathrm{H}), 3.40(\mathrm{~s}$, 2H), $2.66 \sim 2.45(\mathrm{~m}, 4 \mathrm{H}) ;{ }^{13} \mathrm{C} \mathrm{NMR}\left(101 \mathrm{MHz}, \mathrm{CDCl}_{3}\right) \delta$ : $169.9,148.4,141.5,134.3,132.0,130.9,130.0,129.6$, 127.3, 108.5,66.9, 53.6, 52.8. HRMS (ESI) calcd for $\mathrm{C}_{16} \mathrm{H}_{17} \mathrm{ClNO}_{3}[\mathrm{M}+\mathrm{H}]^{+}$306.0891/308.0862, found 306.0886/308.0851.

(Z)-5-(3-Chlorobenzylidene)-3-(morpholinomethyl)furan-2(5H)-one (9d): White solid, yield 78\%. m.p. 114 $115{ }^{\circ} \mathrm{C} ;{ }^{1} \mathrm{H}$ NMR (400 MHz, $\left.\mathrm{CDCl}_{3}\right) \delta: 7.76(\mathrm{~s}, 1 \mathrm{H}), 7.67$ $(\mathrm{dd}, J=7.0,1.6 \mathrm{~Hz}, 1 \mathrm{H}), 7.40 \sim 7.31(\mathrm{~m}, 3 \mathrm{H}), 5.95(\mathrm{~s}, 1 \mathrm{H})$, $3.81 \sim 3.73(\mathrm{~m}, 4 \mathrm{H}), 3.40(\mathrm{~s}, 2 \mathrm{H}), 2.61 \sim 2.53(\mathrm{~m}, 4 \mathrm{H}) .{ }^{13} \mathrm{C}$ NMR $\left(101 \mathrm{MHz}, \mathrm{CDCl}_{3}\right) \delta: 169.8,148.1,141.1,134.7$, 130.0, 129.6, 129.0, 128.5, 111.7, 66.9, 53.6, 52.8. HRMS (ESI) calcd for $\mathrm{C}_{16} \mathrm{H}_{17} \mathrm{ClNO}_{3}[\mathrm{M}+\mathrm{H}]^{+} 306.0891 /$ 308.0862, found 306.0886/308.0851.

(Z)-5-(4-Chlorobenzylidene)-3-(morpholinomethyl)furan-2(5H)-one $(9 \mathrm{e})$ : White solid, yield 60\%. m.p. 113 $114{ }^{\circ} \mathrm{C} ;{ }^{1} \mathrm{H}$ NMR (400 MHz, $\left.\mathrm{CDCl}_{3}\right) \delta: 7.73$ (d, $J=8.6$ $\mathrm{Hz}, 2 \mathrm{H}), 7.38$ (d, $J=8.6 \mathrm{~Hz}, 2 \mathrm{H}), 7.29$ (s, 1H), 5.98 (s, $1 \mathrm{H}), 3.82 \sim 3.65(\mathrm{~m}, 4 \mathrm{H}), 3.40(\mathrm{~s}, 2 \mathrm{H}), 2.56$ (brs, $4 \mathrm{H}) ;{ }^{13} \mathrm{C}$ NMR $\left(101 \mathrm{MHz}, \mathrm{CDCl}_{3}\right) \delta: 169.9,147.6,141.2,135.1$, 131.6, 129.1, 112.0, 66.9, 61.0, 56.3, 54.0, 52.8. HRMS (ESI) calcd for $\mathrm{C}_{16} \mathrm{H}_{17} \mathrm{ClNO}_{3}[\mathrm{M}+\mathrm{H}]^{+} 306.0891 /$ 308.0862, found 306.0886/308.0851.

(Z)-5-(2-Methoxybenzylidene)-3-(morpholinomethyl)furan-2(5H)-one (9f): Light yellow solid, yield 40\%. m.p. 98 $99{ }^{\circ} \mathrm{C} ;{ }^{1} \mathrm{H}$ NMR $\left(400 \mathrm{MHz}, \mathrm{CDCl}_{3}\right) \delta: 7.73(\mathrm{~d}, J=8.6$ $\mathrm{Hz}, 2 \mathrm{H}), 7.38$ (overlap, 3H), $5.97(\mathrm{~s}, 1 \mathrm{H}), 3.83$ (s, 3H), $3.81 \sim 3.73(\mathrm{~m}, 4 \mathrm{H}), 3.40(\mathrm{~s}, 2 \mathrm{H}), 2.64 \sim 2.51(\mathrm{~m}, 4 \mathrm{H}) ;{ }^{13} \mathrm{C}$ NMR (101 MHz, $\left.\mathrm{CDCl}_{3}\right) \delta: 170.1,159.8,147.5,141.3$, 134.2, 129.8, 128.8, 123.3, 115.3, 113.3, 66.9, 55.4, 53.6, 52.8. HRMS (ESI) calcd for $\mathrm{C}_{17} \mathrm{H}_{20} \mathrm{NO}_{4}[\mathrm{M}+\mathrm{H}]^{+}$ 302.1387 , found 302.1373 .

(Z)-5-(3-Methoxybenzylidene)-3-(morpholinomethyl)furan-2(5H)-one $(9 \mathrm{~g})$ : Yellow solid, yield 67\%. m.p. 96 
$97{ }^{\circ} \mathrm{C} ;{ }^{1} \mathrm{H} \mathrm{NMR}\left(400 \mathrm{MHz}, \mathrm{CDCl}_{3}\right) \delta: 7.32 \sim 7.36$ (overlap, 4H), $6.91(\mathrm{~d}, J=8.1 \mathrm{~Hz}, 1 \mathrm{H}), 5.99$ (s, 1H), 3.87 $(\mathrm{s}, 3 \mathrm{H}), 3.81 \sim 3.71(\mathrm{~m}, 4 \mathrm{H}), 3.39(\mathrm{~s}, 2 \mathrm{H}), 2.61 \sim 2.52(\mathrm{~m}$, $4 \mathrm{H}) ;{ }^{13} \mathrm{C}$ NMR $\left(101 \mathrm{MHz}, \mathrm{CDCl}_{3}\right) \delta: 170.1,159.8,147.5$, $141.3,134.2,129.8,128.8,123.3,115.3,113.3,66.9,55.4$, 53.6, 52.8. HRMS (ESI) calcd for $\mathrm{C}_{17} \mathrm{H}_{20} \mathrm{NO}_{4}[\mathrm{M}+\mathrm{H}]^{+}$ 302.1387 , found 302.1373 .

(Z)-5-(4-methoxybenzylidene)-3-(morpholinomethyl)furan-2(5H)-one $(9 \mathbf{h})$ : Light yellow solid, yield 60\%. m.p. 95 96 ${ }^{\circ} \mathrm{C} ;{ }^{1} \mathrm{H}$ NMR $\left(400 \mathrm{MHz}, \mathrm{CDCl}_{3}\right) \delta: 7.76(\mathrm{~d}, J=8.6$ $\mathrm{Hz}, 2 \mathrm{H}), 7.36$ (d, J=8.6 Hz, 2H), 6.93 (s, 1H), 5.97 (s, $1 \mathrm{H}), 3.83(\mathrm{~s}, 3 \mathrm{H}), 3.82 \sim 3.65(\mathrm{~m}, 4 \mathrm{H}), 3.40(\mathrm{~s}, 2 \mathrm{H}), 2.56$ (brs, $4 \mathrm{H}) .{ }^{13} \mathrm{C}$ NMR $\left(101 \mathrm{MHz}, \mathrm{CDCl}_{3}\right) \delta: 170.6,160.4$, 145.4, 141.6, 132.3, 127.1, 125.4, 113.6, 66.9, 61.0, 56.3, 53.6, 52.8. HRMS (ESI) calcd for $\mathrm{C}_{17} \mathrm{H}_{20} \mathrm{NO}_{4}[\mathrm{M}+\mathrm{H}]^{+}$ 302.1387 , found 302.1373 .

(Z)-3-(morpholinomethyl)-5-(3,4,5-trimethoxybenzylidene)furan-2(5H)-one (9i): Yellow solid, yield 50\%. m.p. $120 \sim 121{ }^{\circ} \mathrm{C} ;{ }^{1} \mathrm{H}$ NMR (400 MHz, $\left.\mathrm{CDCl}_{3}\right) \delta: 7.32(\mathrm{~s}, 1 \mathrm{H})$, 7.02 (s, 2H), $5.91(\mathrm{~s}, 1 \mathrm{H}), 3.90(\mathrm{~d}, J=6.7 \mathrm{~Hz}, 9 \mathrm{H}), 3.71 \sim$ 3.74 (overlap, $4 \mathrm{H}), 3.37$ (s, $2 \mathrm{H}), 2.57 \sim 2.48(\mathrm{~m}, 4 \mathrm{H}) ;{ }^{13} \mathrm{C}$ NMR $\left(101 \mathrm{MHz}, \mathrm{CDCl}_{3}\right) \delta: 170.1,153.3,146.8,141.3$, $139.4,128.5,128.1,113.5,107.9,66.9,61.0,56.3,53.6$, 52.8. HRMS (ESI) calcd for $\mathrm{C}_{19} \mathrm{H}_{24} \mathrm{NO}_{6}[\mathrm{M}+\mathrm{H}]{ }^{+}$ 362.1598 , found 362.1587 .

(Z)-5-(2,3-dimethoxybenzylidene)-3-(morpholinomethyl)furan-2(5H)-one (9j): White solid, yield 46\%. m.p. 108 $109{ }^{\circ} \mathrm{C} ;{ }^{1} \mathrm{H}$ NMR (400 MHz, $\left.\mathrm{CDCl}_{3}\right) \delta: 7.84$ (d, $J=$ $8.1 \mathrm{~Hz}, 1 \mathrm{H}), 7.42(\mathrm{~s}, 1 \mathrm{H}), 7.12(\mathrm{t}, J=8.1 \mathrm{~Hz}, 1 \mathrm{H}), 6.93$ (d, $J=7.0 \mathrm{~Hz}, 1 \mathrm{H}), 6.52(\mathrm{~s}, 1 \mathrm{H}), 3.91(\mathrm{~s}, 3 \mathrm{H}), 3.89(\mathrm{~s}, 3 \mathrm{H})$, $3.79 \sim 3.74(\mathrm{~m}, 4 \mathrm{H}), 3.40(\mathrm{~s}, 2 \mathrm{H}), 2.60 \sim 2.53(\mathrm{~m}, 4 \mathrm{H}) ;{ }^{13} \mathrm{C}$ NMR $\left(101 \mathrm{MHz}, \mathrm{CDCl}_{3}\right) \delta: 170.3,152.6,147.9,141.8$, $128.5,127.2,123.1,113.3,107.2,61.4,55.8,53.6,52.8$, 29.7. HRMS (ESI) calcd for $\mathrm{C}_{18} \mathrm{H}_{22} \mathrm{NO}_{5}[\mathrm{M}+\mathrm{H}]^{+}$ 332.1492, found 332.1490.

(Z)-5-(4-fluorobenzylidene)-3-(morpholinomethyl)furan-2(5H)-one (9k): Light yellow solid, yield 77\%. m.p. 116 $117{ }^{\circ} \mathrm{C}$; ${ }^{1} \mathrm{H}$ NMR (400 MHz, $\left.\mathrm{CDCl}_{3}\right) \delta: 7.79(\mathrm{~m}$, 2H), $7.37(\mathrm{~s}, 1 \mathrm{H}), 7.11(\mathrm{~m}, 2 \mathrm{H}), 5.98(\mathrm{~s}, 1 \mathrm{H}), 3.81 \sim 3.70$ (m, 4H), 3.39 (s, 2H), $2.61 \sim 2.50(\mathrm{~m}, 4 \mathrm{H}) ;{ }^{13} \mathrm{C}$ NMR (101 $\left.\mathrm{MHz}, \mathrm{CDCl}_{3}\right) \delta: 170.1,164.2,161.7,147.0,141.2,132.5$, 129.3, 128.6, 116.1, 115.9, 112.1, 66.9, 53.6, 52.8. HRMS (ESI) calcd for $\mathrm{C}_{16} \mathrm{H}_{17} \mathrm{FNO}_{3}[\mathrm{M}+\mathrm{H}]^{+} 290.1187$, found 290.1171 .

(Z)-5-(4-(tert-Butyl)benzylidene)-3-(morpholinomethyl)-furan-2(5H)-one (9l): White solid, yield 55\%. m.p. $145 \sim 146{ }^{\circ} \mathrm{C} ;{ }^{1} \mathrm{H}$ NMR $\left(400 \mathrm{MHz}, \mathrm{CDCl}_{3}\right) \delta: 7.81 \sim 7.67$ $(\mathrm{d}, J=8.5 \mathrm{~Hz}, 2 \mathrm{H}), 7.44(\mathrm{~d}, J=8.5 \mathrm{~Hz}, 2 \mathrm{H}), 7.29$ (s, 1H), $6.09(\mathrm{~s}, 1 \mathrm{H}), 3.92 \sim 3.78(\mathrm{~m}, 4 \mathrm{H}), 3.52(\mathrm{~s}, 2 \mathrm{H}), 2.72$ (brs, $4 \mathrm{H}), 1.35(\mathrm{~s}, 9 \mathrm{H}) ;{ }^{13} \mathrm{C}$ NMR $\left(101 \mathrm{MHz}, \mathrm{CDCl}_{3}\right) \delta: 170.2$, $150.5,147.2,137.5,130.7,129.9,128.0,126.3,66.9,53.6$, 52.8, 34.1, 29.7, 23.8. HRMS (ESI) calcd for $\mathrm{C}_{20} \mathrm{H}_{26} \mathrm{NO}_{3}$ $[\mathrm{M}+\mathrm{H}]^{+}$328.1907, found 328.1918.

(Z)-5-(4-Isopropylbenzylidene)-3-(morpholinomethyl)furan-2(5H)-one (9m): Light yellow solid, yield 47\%. m.p. 98 99 ${ }^{\circ} \mathrm{C} ;{ }^{1} \mathrm{H}$ NMR (400 MHz, $\left.\mathrm{CDCl}_{3}\right) \delta: 7.73(\mathrm{~d}, J=8.3$ $\mathrm{Hz}, 2 \mathrm{H}), 7.37$ (s, 1H), 7.28 (d, J=8.4 Hz, 2H), 6.01 (s,
1H), 3.75 (overlap, 4H), $3.39(\mathrm{~s}, 2 \mathrm{H}), 3.03 \sim 2.85(\mathrm{~m}, 1 \mathrm{H})$, 2.54 (overlap, 4H), $1.26(\mathrm{~d}, J=8.3 \mathrm{~Hz}, 6 \mathrm{H}) ;{ }^{13} \mathrm{C} \mathrm{NMR}$ $\left(101 \mathrm{MHz} \mathrm{CDCl}_{3}\right) \delta: 170.4,150.5,146.8,141.5,130.7$, $128.0,127.0,113.7,53.6,52.8,34.1,29.7,23.8$. HRMS (ESI) calcd for $\mathrm{C}_{19} \mathrm{H}_{24} \mathrm{NO}_{3}[\mathrm{M}+\mathrm{H}]^{+} 314.1751$, found 314.1755 .

(Z)-5-(4-(4-methylpiperazin-1-yl)benzylidene)-3(morpholinomethyl)furan-2(5H)-one (9n): Yellow soild, yield $16 \%$. ${ }^{1} \mathrm{H}$ NMR (400 MHz, $\left.\mathrm{CDCl}_{3}\right) \delta: 7.73 \sim 7.67(\mathrm{~d}$, $J=9.0 \mathrm{~Hz}, 2 \mathrm{H}), 7.31(\mathrm{~s}, 1 \mathrm{H}), 6.88(\mathrm{~d}, J=9.0 \mathrm{~Hz}, 2 \mathrm{H}), 5.93$ (s, 1H), $3.77 \sim 3.70$ (overlap, $J=4.1 \mathrm{~Hz}, 4 \mathrm{H}), 3.36(\mathrm{~s}, 2 \mathrm{H})$, $3.31 \sim 3.34$ (overlap, $J=11.8,6.7 \mathrm{~Hz}, 4 \mathrm{H}$ ), 2.57 (brd, 6.7 $\mathrm{Hz}, 4 \mathrm{H}), 2.52$ (brd, 4H), 2.47 (s, 3H); ${ }^{13} \mathrm{C}$ NMR (101 MHz, $\left.\mathrm{CDCl}_{3}\right) \delta: 151.3,141.5,132.2,130.4,126.1,123.7,115.4$, $114.9,66.9,54.8,53.6,53.6,48.0,47 . .7,46.1$. HRMS (ESI) calcd for $\mathrm{C}_{19} \mathrm{H}_{24} \mathrm{NO}_{3}[\mathrm{M}+\mathrm{H}]^{+}$370.2125, found 370.2134 .

(Z)-5-(3-Fluoro-4-(4-methylpiperazin-1-yl)benzylidene)-3-(morpholinomethyl)furan-2(5H)-one (9o): Yellow soild, yield 19\%. ${ }^{1} \mathrm{H}$ NMR (400 $\left.\mathrm{MHz}, \mathrm{CDCl}_{3}\right) \delta$ : 7.57 (dd, $J=14.4,1.9 \mathrm{~Hz}, 1 \mathrm{H}), 7.39$ (dd, $J=8.5,1.7 \mathrm{~Hz}, 1 \mathrm{H}), 7.31$ $(\mathrm{s}, 1 \mathrm{H}), 6.92$ (t, $J=20.5,8.9 \mathrm{~Hz}, 1 \mathrm{H}), 5.90(\mathrm{~s}, 1 \mathrm{H}), 3.76 \sim$ 3.70 (overlap, $4 \mathrm{H}$ ), 3.37 (s, 2H), $3.24 \sim 3.15$ (overlap, $4 \mathrm{H}$ ), $2.64 \sim 2.57(\mathrm{~m}, 4 \mathrm{H}), 2.55 \sim 2.49(\mathrm{~m}, 4 \mathrm{H}) ;{ }^{13} \mathrm{C}$ NMR $(101$ $\left.\mathrm{MHz}, \mathrm{CDCl}_{3}\right) \delta: 170.2,146.5,141.2,136.2,133.4,127.4$, $118.4,112.5,66.9,55.0,53.7,53.6,52.8,49.9,46.1$. HRMS (ESI) calcd for $\mathrm{C}_{21} \mathrm{H}_{27} \mathrm{FN}_{3} \mathrm{O}_{3}[\mathrm{M}+\mathrm{H}]^{+}$388.2031, found 388.2035.

5-Cyclohexylidene-3-(morpholinomethyl)furan-2(5H)one (9p): Light yellow solid, yield 42\%. m.p. 109 $110{ }^{\circ} \mathrm{C} ;{ }^{1} \mathrm{H}$ NMR (400 MHz, DMSO) $\delta: 7.96$ (s, 1H), $3.61 \sim 3.55$ (overlap, $4 \mathrm{H}$ ), 3.22 (s, 2H), 2.41 (overlap, $8 \mathrm{H}$ ), $1.59(\mathrm{~s}, 6 \mathrm{H}) ;{ }^{13} \mathrm{C}$ NMR (101 MHz, DMSO) $\delta$ : $170.3,142.3$, 137.8, 130.4, 127.5, 66.6, 53.5, 52.5, 28.7, 28.1, 27.3, 26.1. HRMS (ESI) calcd for $\mathrm{C}_{15} \mathrm{H}_{22} \mathrm{NO}_{3}[\mathrm{M}+\mathrm{H}]^{+}$264.1594, found 264.1591 .

4.1.7 Synthesis of (Z)-3-(4-(tert-butyl)benzylidene)indolin-2-one (11)

To a solution of indolin-2-one $(200 \mathrm{mg}, 1.5 \mathrm{mmol})$ in $\mathrm{CH}_{3} \mathrm{OH}(1 \mathrm{~mL})$ was added 4-(tert-butyl)benzaldehyde (365.6 mg, $2.25 \mathrm{mmol}$ ), and the mixture was stirred with ethylenediamine $(10 \mathrm{mg})$ for $10 \mathrm{~h}$ at room temperature. Then, the system was concentrated to remove $\mathrm{CH}_{3} \mathrm{OH}$ and purified by silica gel column chromatography (ethyl acetate/petroleum ether, $V: V=1: 7)$ to give 3 -(4-(tertbutyl)benzylidene)indolin-2-one (11), $68 \mathrm{mg}$, yield $16 \%$ (yellow soild). ${ }^{1} \mathrm{H}$ NMR (400 $\left.\mathrm{MHz}, \mathrm{CDCl}_{3}\right) \delta: 10.59$ (s, $1 \mathrm{H}), 7.66$ (overlap, 3H), $7.61(\mathrm{~s}, 1 \mathrm{H}), 7.55(\mathrm{~d}, J=8.3 \mathrm{~Hz}$, 2H), $7.24(\mathrm{~d}, J=7.8 \mathrm{~Hz}, 1 \mathrm{H}), 6.88(\mathrm{t}, J=7.9 \mathrm{~Hz}, 2 \mathrm{H}), 1.33$ $(\mathrm{s}, 9 \mathrm{H}) ;{ }^{13} \mathrm{C}$ NMR $\left(101 \mathrm{MHz}, \mathrm{CDCl}_{3}\right) \delta: 174.0,158.0$, $148.1,141.0,136.8,135.2,134.6,132.1,130.8,127.6$, 126.3, 126.2, 115.3, 39.9, 36. HRMS (ESI) calcd for $\mathrm{C}_{19} \mathrm{H}_{20} \mathrm{NO}[\mathrm{M}+\mathrm{H}]^{+}$278.1539, found 278.1544.

4.1.8 Synthesis of (Z)-3-(4-(tert-butyl)benzylidene)-1((tetra-hydro-2H-pyran-4-yl)methyl)indolin-2-one (12)

Under ice bath conditions, to a solution of 3-(4-(tert- 
butyl)benzylidene)indolin-2-one $(25 \mathrm{mg}, 0.09 \mathrm{mmol})$ in DMF (1 mL) was added $\mathrm{NaH}(7.22 \mathrm{mg}, 0.3 \mathrm{mmol})$, and the mixture was stirred for $30 \mathrm{~min}$. Then, 4-(bromomethyl)tetrahydro- $2 H$-pyran $(24 \mu \mathrm{L}, 0.16 \mathrm{mmol})$ was added to the system. After reacting for $9 \mathrm{~h}$, the mixture was diluted into water $(10 \mathrm{~mL})$ and extracted with ethyl acetate $(10 \mathrm{~mL} \times 4)$. The combined organic layers were dried over $\mathrm{MgSO}_{4}$, concentrated, and purified by silica gel column chromatography $[V$ (acetone) $: V$ (petroleum ether $)=1: 5]$ to give 3-(4-(tert-butyl)-benzylidene)-1-(tetrahydro-2 H-pyran-4yl)-indolin-2-one (12), $14 \mathrm{mg}$, yield $44 \%$ (yellow oil). ${ }^{1} \mathrm{H}$ NMR (400 MHz, $\left.\mathrm{CDCl}_{3}\right) \delta: 7.43(\mathrm{~d}, J=7.9 \mathrm{~Hz}, 2 \mathrm{H}), 7.38$ $(\mathrm{d}, J=8.2 \mathrm{~Hz}, 2 \mathrm{H}), 7.25(\mathrm{t}, J=7.2 \mathrm{~Hz}, 1 \mathrm{H}), 6.88$ (d, $J=7.8$ $\mathrm{Hz}, 1 \mathrm{H}), 6.78$ (t, $J=7.8 \mathrm{~Hz}, 1 \mathrm{H}), 6.55(\mathrm{~d}, J=7.5 \mathrm{~Hz}, 1 \mathrm{H})$, 4.80 (s, 1H), 3.99 (d, $J=10.2 \mathrm{~Hz}, 2 \mathrm{H}), 3.67$ (d, $J=7.2$ $\mathrm{Hz}, 2 \mathrm{H}), 3.35$ (t, $J=11.5 \mathrm{~Hz}, 2 \mathrm{H}), 2.12 \sim 2.08(\mathrm{~m}, 1 \mathrm{H})$, $1.63(\mathrm{~d}, J=12.8 \mathrm{~Hz}, 2 \mathrm{H}), 1.53 \sim 1.44(\mathrm{~m}, 2 \mathrm{H}), 1.33(\mathrm{~s}$, 9H). HRMS (ESI) calcd for $\mathrm{C}_{25} \mathrm{H}_{30} \mathrm{NO}_{2}[\mathrm{M}+\mathrm{H}]^{+}$ 376.2271, found 376.2278.

\subsection{Biological evalution}

\subsubsection{Material}

Fetal bovine serum (FBS), Roswell Park Memorial Institute 1640 (RPMI-1640) medium, MEM, DMEM, and penicillin-streptomycin were purchased from HyClone (Victoria, Australia). MTT, NAC, and Z-VAD-fmk were purchased from Selleck Chemicals (Houston, TX). The FITC/Annexin V Apoptosis Detection Kit was purchased from BestBio (Shanghai, China). DCFH-DA and diaminobenzidine (DAB) were purchased from Beyotime Biotechnology (Shanghai, China). Antibodies specific for actin, caspase-3, and PARP were obtained from Santa Cruz Biotechnology (Santa Cruz, CA). Antibodies specific for caspase-9was purchased from Cell Signaling Technology (Danvers, MA). The antibody specific for survivin, cleaved caspase-3, and cleaved caspase-9 were purchased from Abcam (Cambridge, MA). Peroxidase labeled anti-rabbit, anti-mouse, and anti-goat polyclonal immunoglobulins were purchased from Bioss (Shanghai, China). The enhanced chemiluminescence (ECL) kit was purchased from Thermo Fisher Scientific (Waltham, MA).

All the tested compounds were dissolved in dimethyl sulfoxide (DMSO) to $10 \mathrm{mmol} / \mathrm{L}$ stock solutions and stored at $-20{ }^{\circ} \mathrm{C}$. For each experiment, the stock solutions were diluted in the culture medium to obtain the desired concentration. The final DMSO content in cell culture was $\leqslant 0.5 \%$ (volume fraction), which was found to be nontoxic to cells.

\subsubsection{Cell lines and cultures}

Human gastric cancer cell lines (MGC803, HGC27, and SGC7901) and human gastric epithelial cells (GES1) were obtained from the American Type Culture Collection (ATCC, Manassas, VA) and cultured at $37{ }^{\circ} \mathrm{C}$ in an atmosphere containing $5 \% \mathrm{CO}_{2}$, with $10 \%$ heat-inactivated fetal bovine serum supplemented with RPMI1640 medium, $100 \mathrm{U} / \mathrm{mL}$ penicillin, and $0.1 \mathrm{mg} / \mathrm{mL}$ streptomycin. All cell lines were from ATCC and were cultured under standard conditions as recommended by the supplier.

\subsubsection{Analysis of cell proliferation}

For MGC803 cells, cell survival rates were determined by MTT assay. The cells were seeded in a 96-well plate (4000 well) for $24 \mathrm{~h}$, followed by adding solution of compounds $(200 \mu \mathrm{mol} / \mathrm{L})$ to the respective wells in the indicated final concentrations and incubated for $24 \mathrm{~h}$. Then, 20 $\mu \mathrm{L}$ of $5 \mathrm{mg} / \mathrm{mL}$ MTT was added to the medium, and the cells were incubated for $4 \mathrm{~h}$ at $37{ }^{\circ} \mathrm{C}$ and $5 \% \mathrm{CO}_{2}$. After removal of the culture medium, $150 \mu \mathrm{L}$ of DMSO was added to dissolve the formazan crystals. The absorbance was read by an enzyme labeling instrument with a 490-nm wavelength resolution. The viability of untreated cells was set as $1008 \%$, and the viability of the other groups was calculated by comparing the optical density reading of the control cells. The $\mathrm{IC}_{50}$ values were calculated by nonlinear regression analysis.

\subsubsection{Apoptosis analysis}

The cells were treated with different concentrations of compound 91 for $24 \mathrm{~h}$. Cells were collected and washed with PBS twice, and incubated with fluorescein isothiocyanate (FITC) conjugated annexin $\mathrm{V}$ by use of anannexin V/FITC apoptosis kit following the step-by-step protocol provided by the manufacturer. Annexin $\mathrm{V}+/ \mathrm{PI}-$ cells were considered as early apoptotic and Annexin $\mathrm{V}+/ \mathrm{PI}+$ cells as late apoptotic/necrotic.

\subsubsection{Western blot analysis}

MGC803 cells were seeded in a 100-mm tissue culture plate, cultivated for $24 \mathrm{~h}$, and then treated with different concentrations of compound 91 for $24 \mathrm{~h}$. After treatment, cells were collected and lysed with ice-cold lysis buffer (Beyotime, Shanghai, China). Protein concentrations of the lysates were determined by a micro-BCA protein assay kit. After centrifugation at $12000 \mathrm{r} / \mathrm{min}$ for $30 \mathrm{~min}$, the total cellular protein extracts were boiled with $5 \times$ loading buffer, separated by sodium dodecyl sulfate polyacrylamide gel electrophoresis (SDS-PAGE) and transferred to a nitrocellulose membrane. After blocking with 5\% skimmed milk in PBST for $2 \mathrm{~h}$, membranes were incubated with appropriate antibodies overnight at $4{ }^{\circ} \mathrm{C}$, followed by horseradish peroxidase (HRP) conjugated anti-mouse, anti-goat, or anti-rabbit secondary antibodies. The detection of specific proteins was carried out with an enhanced chemiluminescence (ECL) Western blot kit according to the recommended procedure.

Images were captured on a Canon image scanner (LIDE110, Japan). The relative protein levels were calculated by use of $\beta$-actin protein as an endogenous control and quantified by Image $\mathbf{J}$ software.

\subsubsection{Statistical analysis}

The data are expressed as means \pm SD. Significant differences between the groups were determined by the unpaired Student's t-test. $* P<0.05$ and $* * P<0.01$ were accepted as indications of statistical significance. 
Supporting Information The NMR spectra for synthetic compounds. The Supporting Information is available free of charge via the Internet at http://sioc-journal.cn.

\section{References}

[1] Manchoju, A.; Annadate, R. A.; Desquien, L.; Pansare, S. V. Org. Biomol. Chem. 2018, 16, 6224.

[2] Fáková, H.; Pour, M.; Kuneš, J.; Šenel, P. Tetrahedron Lett. 2005, 46, 8137.

[3] David, S.; Peter, B.; Andreas, R.; Wilhelm, S. Toxicol. Lett. 2018, $295,369$.

[4] Dasmahapatra, G.; Lembersky, D.; Son, M. P.; Patel, H.; Peterson, D.; Attkisson, E.; Fisher, R. I.; Friedberg, J. W.; Dent, P.; Grant, S. Mol. Cancer Ther. 2019, 18, 1180.

[5] Germain, A. D. S.; Clavé, G.; Badetdenisot, M. A.; Pillot, J. P.; Cornu, D. Nat. Chem. Biol. 2016, 12, 1552.

[6] Xu, H. W.; Zhao, L. J.; Liu, H. F.; Zhao, D.; Luo, J.; Xie, X. P.; Liu, W. S.; Zheng, J. X.; Dai, G. F.; Liu, H. M.; Liu, L. H.; Liang, Y. B. Bioorg. Med. Chem. Lett. 2014, 24, 2388.
[7] Xu, H.W.; Jia, S. L.; Xie, X. P.; Luo, J.; Wang, S. H. Chin. J. Org. Chem. 2017, 37, 902 (in Chinese).

(徐海伟, 贾世龙, 谢晓平, 罗姣, 王树, 有机化学, 2017, 37, 902.)

[8] Necula, L.; Matei, L.; Dragu, D.; Neagu, A. I.; Mambet, C.; Nedeianu, S.; Bleotu, C.; Diaconu, C. C.; Chivu-Economescu, M. World J. Gastroenterol. 2019, 17, 2029.

[9] Xu, H. W.; Liu, G. Z.; Zhu, S. L.; Hong, G. F.; Liu, H. M.; Wu, Q. Steroids 2010, 75, 419 .

[10] Xu, H. W.; Wang, J. F.; Liu, G. Z.; Hong, G. F.; Liu, H. M. Org. Biomol. Chem. 2007, 5, 1247.

[11] Caroppi, P.; Sinibaldi, F.; Fiorucci, L.; Santucci, R. Curr. Med. Chem. 2009, 16, 4058.

[12] Fulda, S.; Debatin, K. M. Oncogene 2006, 25, 4798.

[13] Danial, N. N.; Korsmeyer, S. J. Cell 2004, 116, 205.

[14] Fulda,S.; Debatin, K. M. Eur. J. Cancer 2005, 41, 786.

[15] Cui, Q; Wang, J. A.; Yang, H. S.; Xie, L. G. Chin. J. Org. Chem. 2010, 30, 1705 (in Chinese).

(崔庆, 王娇, 杨海申, 谢龙观, 徐效华, 有机化学, 2010, 30, 1705.) 